Journal of African Real Estate Research

Volume 3, Issue 2

\title{
Research Notice: A Strategy and Tool for Improving the Visibility of African Real Estate Research
}

\author{
Jonas Hahn ${ }^{1}$, and Karl-Werner Schulte ${ }^{2}$ \\ 1-2 International Real Estate Business School, University Regensburg, Germany
}

To cite this article: Hahn, J. \& Schulte, K. (2018). A Strategy and Tools for Improving the Visibility of African Real Estate Research. Journal of African Real Estate Research, 3(2), pp. 1-8. DOI: $10.15641 /$ jarer.v3i2.677.

\begin{abstract}
The body of knowledge in the context of African Real Estate is constantly growing. The research discipline has attracted increased interest, and thereby, the number of available publications has expanded. As the discipline progresses, it becomes more and more difficult to keep track of the various research avenues and the contemporary research output in African Real Estate. New technology provides a viable solution to the problem as it allows institutions and individuals to track and archive research in an accessible way. Online databases and search engines have changed the way knowledge is accessed and produced. This contribution outlines concepts for promoting research on African Real Estate, exemplified by the AfRER.org Research Database. It presents an outlook on scaling the list of available publications into a dynamic web-based system that will support both authors and researchers alike on their quests for information and data. This paper also makes suggestions on how to involve relevant stakeholders by fostering and developing research peer-groups regarding African Real Estate research output. Entitled, Promoting Publications in African Real Estate Research - Status Quo and Outlook, this topic was initially presented at the 2018 Annual Conference of the African Real Estate Society in Abeokuta, Nigeria.
\end{abstract}

Keywords: Research Output; Publication; Key Performance Indicators; Research Database; Social Networks

\section{An Inconvenient Perception of African Real Estate Research}

Once a year, when a multitude of researchers and practitioners in the field of African Real Estate meet for the annual African Real Estate Society Conference, young talents and experienced players gather to share their newest research and findings. Hearing this exchange and the variety of outcomes, one cannot help but place these pieces of information on the continuum of one's industry-knowledge - how it could influence one's research, how it could improve what is being done at one's institution or which mistakes to avoid when undertaking studies? However, the longevity

\footnotetext{
1 jonas.hahn@irebs.de

2 schulte.irebs@t-online.de
} 
of this knowledge exchange is contextual and often what is learnt fails to materialise in everyday academic work. This is unfortunate as research traditionally benefits from strong academic connection and collaboration. Perhaps, it is this failure to use combined research outputs or cooperation that leaves the academic field of African Real Estate lagging. From a managerial perspective, one must ask: why is that? Was everything possible done to improve the exposure and reutilisation of existing research? What else could have been done?

\section{Generating and Measuring Exposure and Visibility of Research}

In understanding the requirements and expectations of academic output, it is useful to attempt to understand the publication of research using basic economics. Let us suppose that the production, processing and consumption of research is a question of demand and supply like any other good. This particular good, however, comes from a niche supply and demand pattern one that is individual, and certainly limited. The role of quality may impact demand and supply by increasing demand or the acceptance of the work. Contrastingly, quality also illustrates a barrier for academic production as the quality of the good is only ensured when academic standards are met. The relevance of the topic or the outcomes ensures a greater audience and thereby demand. Alternatively, from another economic point of view, one could argue that one's incentive to produce lies in establishing knowledge and in connecting it with one's brand or portfolio, maybe even becoming a market leader in a particular field. One's incentive to consume is premised on a desire to gather knowledge, develop capabilities and, last but not least, to appropriate in individual production activities. In that sense, publishing on African Real Estate is always a social activity in a collaborative and integrated market. It is never a one-way street - at least if a certain level of quality and relevance is exceeded.

The common understanding of measuring the visibility of research is based on key performance indicators including, views (how often was the abstract accessed), downloads (how often was the full paper downloaded) and citations (how many times was the respective work interesting or relevant enough to be a basis for another publication). When speaking of "improving visibility", there are certainly many definitions of visibility amongst researchers. However, we found the following pattern to be a generally accepted indication of performance amongst published research (see Figure $1)$. 


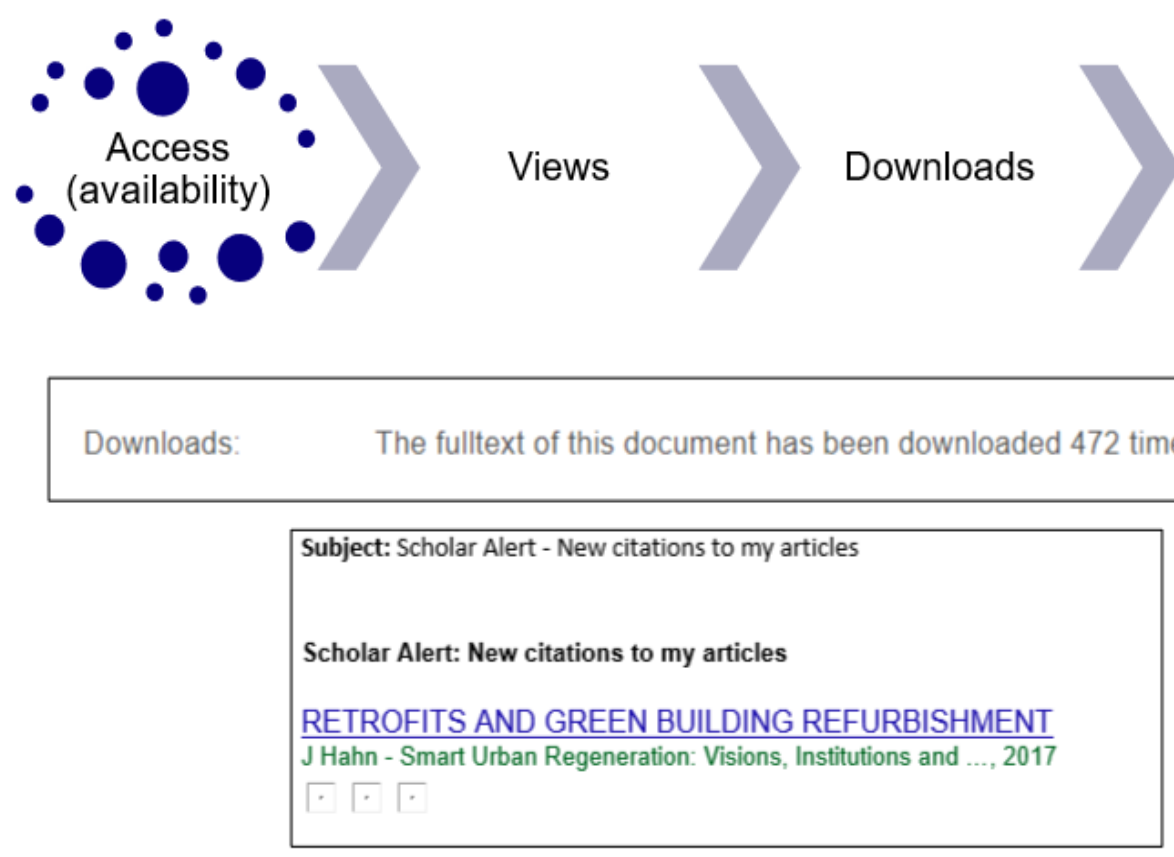

\section{Figure 1: KPIs in Research - "The Chain of Successful Reuse"}

The idea of a multi-layered or rather multi-step evolution of visibility contains a very individual micro-perspective: how do I design my topic and my specific study in a way that is interesting, high-quality and valuable for readership (demand) and citations (reutilisation)? Of course, this is important, as the quality of content is a prerequisite and a unique selling-point of research output.

However, from a strategic (macro) perspective, one must go a step back and ask from a macro perspective: have we as researchers, networks, associations, publishing houses, and last but not least AfRES - done everything to ensure access to other researchers (as it is the basis for any of the further steps in successfully development exposure)?

\section{New Technology Provides Viable Solutions for the Problem}

In the past ten or so years, various online research platforms have evolved. Collectively, they bring together the micro and macro perspective outlined above by addressing both readers and authors and thereby try to overcome the issue of lacking access or transparency in current research. As a basic principle, research databases have attempted to overcome the obstacle of bringing together supply and demand in the field. For instance, EBSCOhost, EconLit and other platforms are very paradigmatic in this regard. Furthermore, they are limited by library access. Google Scholar is a product that tries to add search engine intelligence functionality for its users and thereby may be believed to exceed EBSCOhost or EconLit technologically but does not necessarily cover the same scope or depth as these scientific databases. Similarly, limitations of access may exist for Google Scholar users' due to licensing. In more recent years, the idea of social networking has been added to overcome the demand/supply issue. Platforms such as 
ResearchGate have individualised the regulation of exposure and publication in research and left this, to some extent, to the respective author. And indeed, access to resources help solve the fundamental problem of finding African Real Estate Research. However, are these platforms enough to optimise its exposure?

\section{Promotion of Research - A (Social) Networking Challenge?}

In discussions during this year's AfRES conference, it became apparent that researchers find additional challenges to accessing content. One is licensing models, which are partially global but also limit regional access. A second obstacle, closely related, is the under-funding of some university libraries especially those already struggling to access (digital and current) research content. Another barrier is the differences in terminology when people do not find results due to different expectations regarding the regional vs. continentwide scope of the research. Also, individual preferences of authors concerning access as well as different dimensions of relevance limit the possibilities for researchers (especially younger individuals) to access information. Despite these challenges, there is good news as slow internet connection has become less and less of a problem at many universities. This connectivity is vital for the exchange and production of knowledge internationally.

In the light of the barriers listed above, it seems that generating visibility for one's research is more than a question of hashtags, but as a matter of fact, active involvement and engagement on a different level. It connotes that successfully increasing the exposure and utilisation of one's research output in African Real Estate requires working together to generate benefits and progress for all parties involved. Based on the discussion and findings so far, is it possible to derive some general rules or guidelines for researchers?

\section{Operationalisation of the Strategy}

What do we derive from these strategic considerations? We believe that a productive way to successfully increase the visibility of African Real Estate Research is achievable in line with the following constituents:

1. Provide and acknowledge quality in African Real Estate Research. In this context, it requires the establishment and education of research methods in the community starting from a Bachelor's level.

2. Ensure relevance and improved data transparency by actively interacting with practitioners.

3. Build up micro-networks and research peer-groups and design them openly but premised on a common understanding of aim and quality.

4. Optimise exposure for one's AfRES presentations by sharing with others. 


\section{AfRERDB.org - An Essential Tool for Access and Collaboration}

Sharing with others is quintessential and the ultimate appeal of this discussion paper. The IRE|BS Foundation for African Real Estate Research has been collecting outputs and publications of researchers, who delivered their work and published it on the foundation's website. And, while we find that only a small share of what is being published can be uploaded onto the site, we have always ensured that research performed by Master and $\mathrm{PhD}$ Students at our home university (IRE|BS at University Regensburg) has been included. This could and should also include our partner universities. Figure 2 gives an overview of the original AfRER.org database and selected entry.

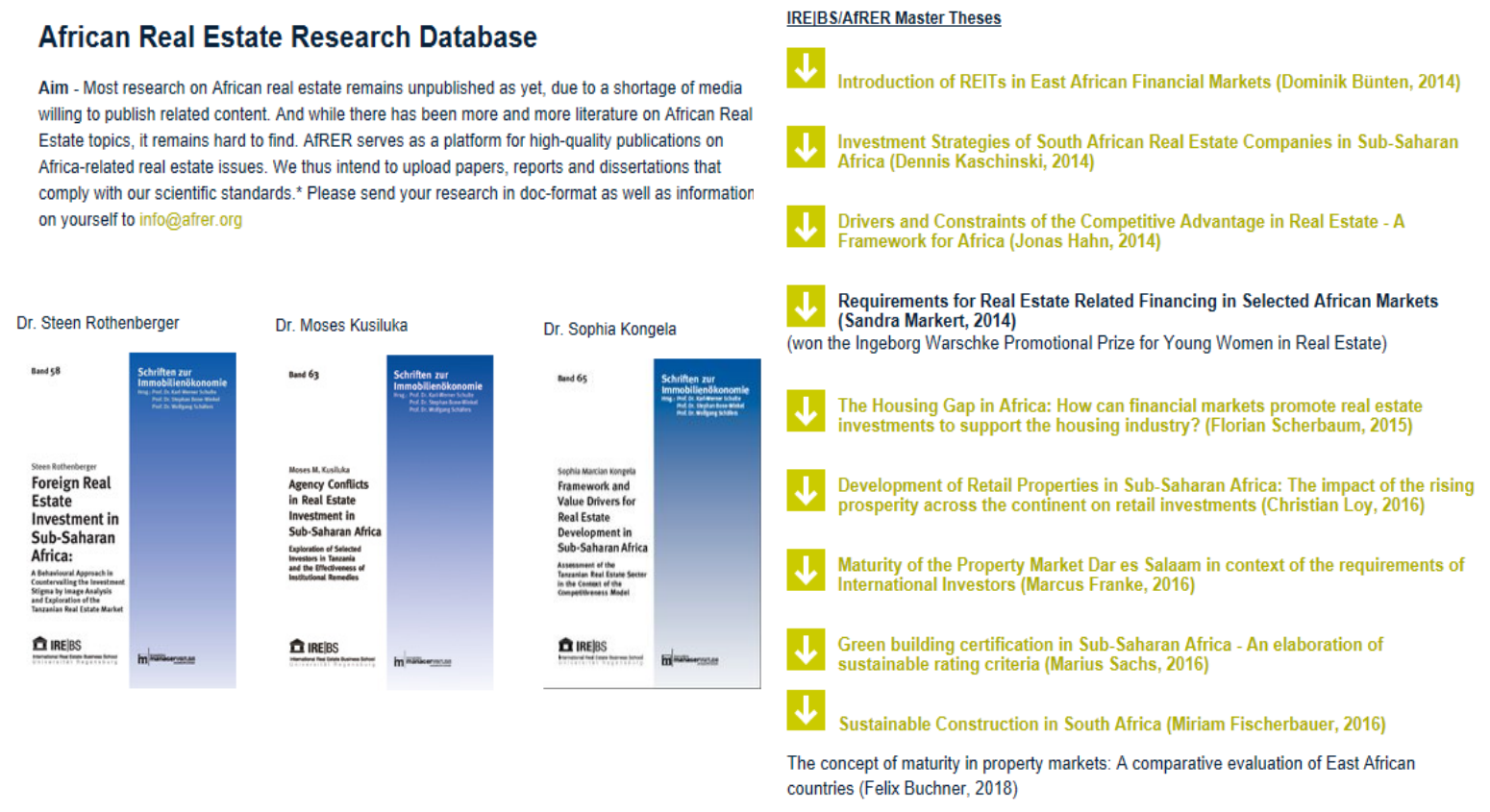

Figure 2: Existing AfRER.org Database

We are happy to announce that we have improved the existing database by launching the project as its own, stand-alone platform at www.afrerdb.org.

This platform systematically collects and circulates African Real Estate research work to make it visible and available to other researchers. Also, the new platform comes with a more powerful search engine and a responsive web-design which adjusts to mobile devices such as tablets or smartphones. Figures $3 \mathrm{a}$ to $3 \mathrm{c}$ give an impression of the new platform and exemplify entries in the database with the site's preview function. 
Journal of African Real Estate Research Volume 3(2) 2018

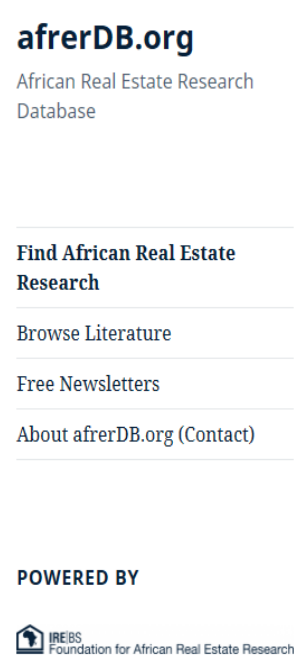

\section{Find African Real Estate} Research

Search here."

Q)

Enter your key words and submit.

We will search our data base for you.

Figure 3a: Home Page www.afrerdb.org - Responsive Design, Clear Layout

foreign direct investment

( Q

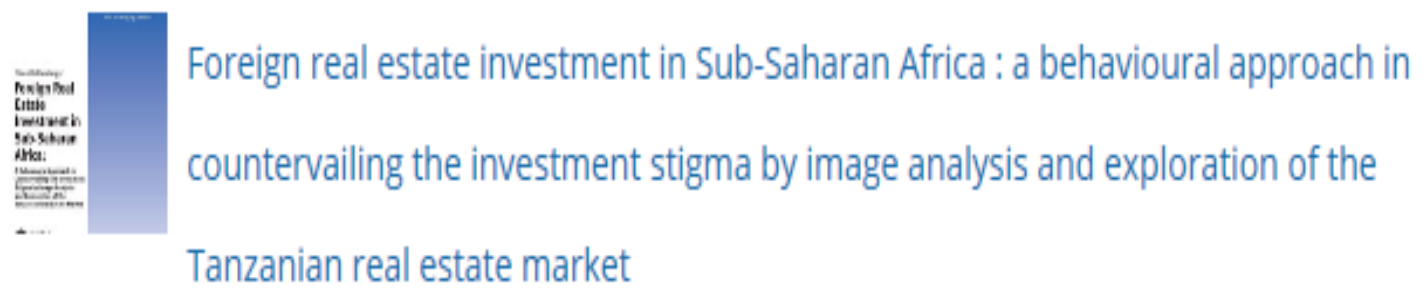

Ph.D. Dissertation of Dr. Steen Rothenberger. Rothenberger, Steen (2010) Foreign real estate...

Figure 3b: Search Result at www.afrerdb.org - with Preview Function 


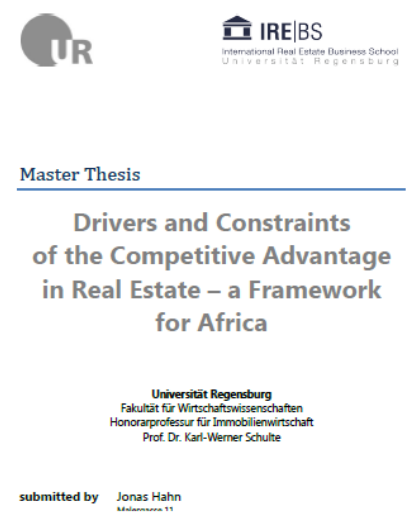

\section{Drivers and Constraints of the Competitive Advantage in Real Estate - a Framework for Africa}

\begin{tabular}{|l|c|}
\hline Download & 3 \\
\hline File Size & $3.00 \mathrm{MB}$ \\
\hline Create Date & July 1, 2018 \\
\hline Download & \\
\hline
\end{tabular}

Figure 3c: Exemplary Entry at www.afrerdb.org - with Download Tracking

This platform is designed and intends to cover the following categories, therefore providing an online location for presenting and sharing African research output on the following:

- AfRES Conference Proceedings and Papers

- Use the valuable outcomes of AfRES conferences

- Showcase high-quality research and detailed information

- Publications of the African Real Estate Research Centre at IRE|BS

- PhD Dissertations to ensure exchange of new research findings

- Master Theses, Bachelor Theses to ensure further use of student's contributions

- Seminar Papers as research briefs or literature overviews (to be discussed)

- Publications of other Universities (Academic Staff, PhD, MSc, BA)

○ Intention: foster international research exchange

$\circ$ Promote collaboration and strengthen networks between institutions

- Journal of African Real Estate Research

O Link to existing website and issues

○ Intention: increase exposure of blind-reviewed content

- Research Papers and Presentations from Other Individuals

○ Working Papers (not necessarily final outputs) 
- Provide content for other researchers of the same field as a call for collaboration

\section{Maintaining and Operating the African Real Estate Research Database}

Despite being fully aware that other platforms may provide additional features, an African Real Estate Research Database intends to provide a structured and targeted platform for collecting, presenting and sharing highquality research in the field. The platform is neither Google nor an own publishing house - and doesn't intend to be either - but rather a collection of relevant academic material and a collaborative archive. Maintaining it and keeping it current requires commitment, activity and involvement - not to mention motivation and communications skills - from all involved parties. Also, the quality gates installed on the platform and its publication process require knowledge and understanding concerning legal topics and quality standards in research. For the moment, a team of non-profit IRE|BS Foundation for African Real Estate Research members are covering these tasks. However, this can change at any time, based on the honest conviction of other institutions to complete these tasks as efficiently as we can. The African Real Estate Research Database is a platform based on the opinion that African Real Estate Research is not a once-a-year event, but continuous collaboration requiring coverage.

To conclude, we believe that the African Real Estate Research Database is not the answer to "everything", but a positive step in the progress of the field. Therefore, this paper cordially invites everyone who finds him or herself in the list of potential research outputs for the database to get in touch with us for further consideration, potential inclusion and sharing with other researchers. Our contact information is provided on the website.

\section{Related Links}

- African Real Estate Database (http://www.afrerdb.org)

- IRE|BS Foundation for African Real Estate Research (http://www.afrer.org)

- EBSCO Host (http://search.epnet.com)

- EconLit (http://www.aeaweb.org/econlit/)

- Google Scholar (http://scholar.google.com)

- ResearchGate (http://www.researchgate.net) 